\title{
Penicillinase-based enzyme-linked immunosorbent assay for the detection of plant viruses:
}

\author{
M.R. Sudarshana and D.Y.R. Reddy \\ Legumes Pathology, International Crops Research Institute for the Semi-Arid Tropics (ICRISAT), \\ Patancheru, A.P. 502 324, India
}

(Accepted 31 May 1989)

\section{Summary}

A penicillinase (PNC)-based, enzyme-linked immunosorbent assay (ELISA) was standardized to detect maize mosaic virus (MMV) in sorghum leaf extracts, peanut mottle virus (PMV) in pea leaf extracts, and tomato spotted wilt virus (TSWV) in peanut leaf extracts, Rabbit $\mathrm{Fc}$-specific antibodies were conjugated with PNC by a single step glutaraldehyde bridge. Among several indicators tested, bromothymol blue (BTB) was found suitable for measuring PNC activity under simulated conditions. Two reagents, starch-iodine complex (SIC) and a mixed $\mathrm{pH}$ indicator, containing bromocresol purple and BTB (2:1) used earlier for the PNCbased ELISA, were compared with BTB for utilization in the PNC-based ELISA. SIC gave a slightly higher virus titre than BTB or the mixed $\mathrm{pH}$ indicator, but it often gave nonspecific reactions. Sodium or potassium salts of penicillin- $G$ at 0.5 $-1.0 \mathrm{mg} / \mathrm{ml}$ and BTB at $0.2 \mathrm{mg} / \mathrm{ml}$ were found to be suitable as substrate-indicator mixture for PNC-based ELISA. The sensitivity of the PNC system was comparable to those of the alkaline phosphatase (ALP) and horseradish peroxidase (HRP) systems in detecting MMV, PMV, and TSWV. The PNC conjugate could be used at a greater dilution than those of the ALP and HRP conjugates and the $B$ TB substrate mixture was stable for at least 3 weeks at $4^{\circ} \mathrm{C}$. Penicillin is readily available in developing countries, and at a substantially lower cost than $p$-nitrophenyl phosphate, the commonly used substrate for ALP in the plate ELISA. Thus the PNCbased ELISA provides a less expensive means for assaying plant viruses by ELISA.

ELISA; Bromothymol blue; Penicillinase; Maize mosaic virus; Peanut mottle virus; Tomato spotted wilt virus

Correspondence to: D.V.R. Reddy, Legumes Pathology, ICRISAT, Patancheru A.P. 502 324, India.

* Submitted as ICRISAT Article No. 834.

0166-0934/89/\$03.50 (C) 1989 Elsevier Science Publishers B.V. (Biomedical Division) 


\section{Introduction}

The enzyme-linked immunosorbent assay (ELISA) is, by far, the most widely used serological test for detecting plant viruses. Two enzymes that have been widely used in the ELISA for the detection of plant viruses are alkaline phosphatase (ALP) (EC 3.1.3.1) and horseradish peroxidase (HRP) (EC 1.11.1.7) (Clark and Bar-Joseph, 1984). Both of these enzymes have problems associated with their use. These include high cost, limited availability, the potential carcinogenic activity of some of the substrates, and the hazardous nature of the hydrolyzed products of the substrates. $\beta$-Lactamase (EC 3.5.2.6), generally known as penicillinase (PNC), has been used in the ELISA (Joshi et al., 1978; Premier et al., 1985; Talwar et al., 1983; Yolken et al., 1984). PNC has several features that make it a clesirable enzyme label for ELISA tests. It has a relatively small molecular weight $(24 \mathrm{kDa}$ ), a high turnover rate, is not too expensive, and is more readily available in developing countries than the other enzymes. Additionally, hydrolyzed products in PNC assays are not known to be hazardous (Joshi et al., 1978).

Several methods have been used to detect the activity of PNC (Ross and O'Callaghan, 1975). So far, two methods have been successfully used in the ELISA for the estimation of penicilloic acid produced due to hydrolysis of penicillin by the enzyme. In the microiodometric method, a standard method used to test PNC activity, reduction of iodine in a starch-iodine complex (SIC) by penicilloic acid results in complete loss of the blue color of SIC (Joshi et al., 1978). Premier et al. (1985) used a mixed pH indicator, consisting of bromocresol purple (BCP) and bromothymol blue (BTB) $(2: 1)$, to measure the penicilloic acid produced due to $\mathrm{PNC}$ activity. In this paper, we evaluate different $\mathrm{pH}$ indicators for their usefulness in the PNC-based ELISA and compare the SIC and the mixed pH indicator $(B C P+B T B)$ with BTB alone for the application of PNC-based ELISA to detect plant viruses; we also report on a comparison of the PNC-based ELISA with the ALP and HRP systems in detecting three plant viruses.

\section{Materials and Methods}

\section{Viruses}

Maize mosaic virus (MMV) was maintained in sorghum (Sorghum bicolor L. Fybrid CSH 6) by feeding with viruliferous Peregrinus maidis. Peanut mottle virus (PMV) and tomato spotted wilt virus (TSWV) were maintained by mechanical sap inoculations in peas (Pisum sativum L., cv. Bonneville) and in peanut (Arachis hypogaea L., cv. TMV 2), respectively. All the virus-infected plants were maintained in a glasshouse at $25-27^{\circ} \mathrm{C}$.

\section{Antisera}

All antisera were produced at the International Crops Research Institute for the Semi-Arid Tropics (ICRISAT), lyophilized, and stored at $-70^{\circ} \mathrm{C}$ until required. 
Enzyme conjugates and substrates

Rabbit Fc-specific antibodies produced in goats (Cappel Laboratories, Cochranville, PA 19330, U.S.A.) were conjugated to ALP by the single step glutaraldehyde methọ (Clark and Adams, 1977). The HRP conjugate of rabbit Fc-specific antibodies was prepared by the periodate oxidation method (Barbara and Clark, 1982). The ALP and HRP conjugates were used at a 1:1000 dilution, which gave optimal reactions for the three viruses, MMV, PMV, and TSWV. The substrate used for ALP was p-nitrophenyl phosphate at $0.25 \mathrm{mg} / \mathrm{ml}$ in diethanolamine buffer. Results were recorded, after a $1 \mathrm{~h}$ incubation, at $405 \mathrm{~nm}$ by an ELISA plate reader (Titertek Multiscan MCC, Flow Laboratories, U.K.). For HRP, 3, 3', 5, 5'-tetramethyl benzidine (Kirkegaard \& Perry Laboratories, MD 20879, U.S.A.) was used as substrate and after $60 \mathrm{~min}$ the reaction was stopped by adding $100 \mu \mathrm{l}$ of $1 \mathrm{M}$ phosphoric acid. Results were recorded at $450 \mathrm{~nm}$.

\section{PNC-based ELISA}

Highly purified PNC (Sigma P-0389, Sigma Chemicals, St. Louis, MO, U.S.A.) was conjugated to rabbit FC-specific antibodies by the single step glutaraldehyde method (Clark and Adams, 1977). The conjugate was stored at $4^{\circ} \mathrm{C}$. Unless otherwise indicated, sodium penicillin-G (provided as a free sample by the Hindusthan Antibiotics, Pimpri, Maharashtra, India) was used in all experiments. When $\mathrm{BCP}+\mathrm{BTB}$ was used, $5.8 \mathrm{mg}$ of $\mathrm{BCP}$ and $2.9 \mathrm{mg}$ of $\mathrm{BTB}$ were dissolved in $50 \mathrm{ml}$ of $0.2 \mathrm{M} \mathrm{NaOH}$ and neutralized by $\mathrm{HCl}$; and the volume was adjusted to $100 \mathrm{ml}$ with distilled water. Penicillin at $1.0 \mathrm{mg} / \mathrm{ml}$ was then incorporated, and the $\mathrm{pH}$ adjusted to 7.2. The color change in the dye was from violet blue to deep yellow, depending on the amount of penicilloic acid produced. Absorbance was measured at $450 \mathrm{~nm}$ (Premier et al.; 1985). The SIC was prepared following a modified procedure of that described by Yolken ett al. (1984). Iodine reagent was prepared by dissolving $80 \mathrm{mg}$ potassium iodide and $30 \mathrm{mg}$ iodine in $100 \mathrm{ml}$ of distilled water. Starch solution was prepared by dissolving $20 \mathrm{mg}$ of soluble starch in $2 \mathrm{ml}$ distilled water. Slight warming was necessary to dissolve starch, and it was essential to use freshly prepared starch solution. The substrate mixture was prepared by adding 1 $\mathrm{ml}$ iodine reagent, $2 \mathrm{ml}$ distilled water, and $5 \mathrm{ml} 0.2 \mathrm{M}$ phosphate buffer, $\mathrm{pH} 7.0$, to the starch solution. Penicilin-G was added to the SIC at $0.06 \mathrm{mg} / \mathrm{ml}$. The dark blue SIC was gradually decolorized by the penicilloic acid produced. Absorbance values were measured at $620 \mathrm{~nm}$.

The BTB substrate mixture was prepared by dissolving $20 \mathrm{mg} \mathrm{BTB}$ in $0.2 \mathrm{M}$ $\mathrm{NaOH}$ and neutralized by $\mathrm{HCl}$. The volume was made up to $100 \mathrm{ml}$. Penicillin-G, at $0.5 \mathrm{mg} / \mathrm{ml}$, was incorporated and the $\mathrm{pH}$ adjusted to 7.2 . The color change from blue to greenish yellow to deep yellow, depending on the amount of penicilloic acid produced, was measured at $620 \mathrm{~nm}$. 


\section{ELISA procedure}

The direct antigen coating (DAC) procedure, as described by Hobbs et al. (1987), was used. Plant extracts prepared in carbonate buffer, $\mathrm{pH} 9.6$, containing $0.17 \%$ diethyldithiocarbamate (sodium salt), were applied to wells, followed by addition of various dilutions of crude antisera. The MMV and PMV antisera were used at 1:10000 dilutions, and the TSWV antiserum was used at a 1:1000 dilution. the PMV and TSWV antisera were cross-adsorbed with leaf extracts from healthy plants, as described previously (Hobbs et al., 1987). Then the enzyme-labeled rabbit Fc-specific antibodies were added. Lastly, the substrate mixture was added and incubated for $1 \mathrm{~h}$ at room temperature $\left(25 \pm 2^{\circ} \mathrm{C}\right)$. Each treatment was replicated in three wells. Optical density readings were obtained for each dilution of leaf extracts from healthy and infected plants, by deducting the absorbance value of buffer control. Absorbance values were considered positive if they yielded optical density values of 2 SD greater than the mean optical density of wells coated with healthy plant extracts. All experiments were repeated at least thrice to examine the reproducibility of the results.

For experiments on the stability of substrate for the PNC-ELISA, plates were coated with various dilutions of $P M V$-infected pea leaf extracts at $37^{\circ} \mathrm{C}$ for $1 \mathrm{~h}$, washed in PBS-tween and stored at $-20^{\circ} \mathrm{C}$. When required each plate was thawed at room temperature and utilized for further processing by the ELISA.

\section{Results and Discussion}

\section{Indicators for PNC-based ELISA}

In preliminary experiments, in order to select a suitable $\mathrm{pH}$ indicator for quantifying the $\mathrm{PNC}$ reaction, $\mathrm{pH}$ indicators of $\mathrm{BCP}+\mathrm{BTB}$, used previously (Premier

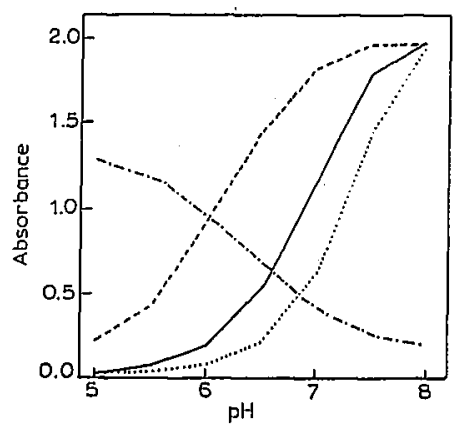

Fig. 1. Comparison of $\mathrm{pH}$ indicators bromocresol purple (BCP) (-.-.-.-), bromothymol blue $(\mathrm{BTB})(-$, phenol red $(\cdots \cdots)$, and mixed pHI indicator of $\mathrm{BCP}+\mathrm{BTB}(-,-$,$) for their re-$ sponse to changes in $\mathrm{pH}$ values. All indicators were prepared in $0.1 \mathrm{M}$ phosphate buffer at different $\mathrm{pH}$ values in wells of a microtitre plate and absorbance values were recordecl at $450 \mathrm{~mm}$ for the mixed $\mathrm{pH}$ indicator, $540 \mathrm{~nm}$ for $\mathrm{BCP}$ and PR, and $620 \mathrm{~nm}$ for BTB. Each point represents the mean absorbance value of three replicate wells. 
et al., 1985) for the PNC-based ELISA, BCP $(0.2 \mathrm{mg} / \mathrm{ml})$, BTB $(0.2 \mathrm{mg} / \mathrm{ml})$, and phenol red (PR) $(0.1 \mathrm{mg} / \mathrm{ml})$ were tested. Optical density readings for $\mathrm{BCP}+\mathrm{BTB}$ at $450 \mathrm{~nm}$ (Premier et al., 1985) and for other indicators at different wavelengths $(405,414,450,492,510,540$ and $620 \mathrm{~nm})$, measurable with the plate reader (Titertek Multiscan MCC 300), in $0.1 \mathrm{M}$ phosphate buffer at $\mathrm{pH}$ values 5.0, 5.5, 6.5, $7.0,7.5$ and 8.0 , were recorded. The wavelength that yielded maximum change in absorbance between pH 5.0 and 7.5 was chosen for each indicator dye and the results are presented in Fig. 1.

The indicators $\mathrm{BCP}, \mathrm{BTB}$, and $\mathrm{PR}$ demonstrated a loss in optical density with increase in acidity. The optical density at $450 \mathrm{~nm}$ for mixed $\mathrm{pH}$ indicator of $\mathrm{BCP}+\mathrm{BTB}$ varied from 0.3 at $\mathrm{pH} 7.5$ to 1.3 at $\mathrm{pH} 5.0$. However, among the other indicators tested, BTB yielded a difference of about $1.8 \mathrm{OD}$ units at $620 \mathrm{~mm}$ between pH 7.5 and 5.0. Thus BTB was chosen for comparison with BCP $+B T B$.

\section{Suitability of different salts of penicillin-G (benzyl penicillin)}

Sodium penicillin-G was initially tested at $0.1,0.2 ; 0.5$ and $1.0 \mathrm{mg} / \mathrm{ml}$ concentrations. With BTB, penicillin $-G$ at concentrations ranging from 0.5 to $1.0 \mathrm{mg} / \mathrm{ml}$ gave the highest titres for PMV. Subsequently potassium and procaine salts were compared with the sodium salt for their suitability in PNC-based ELISA, utilizing BTB. Since sodium and potassium salts gave slightly higher titres than the procaine salt in all.subsequent tests sodium or potassium penicillin-G was used at 0.5 $\mathrm{mg} / \mathrm{ml}$.
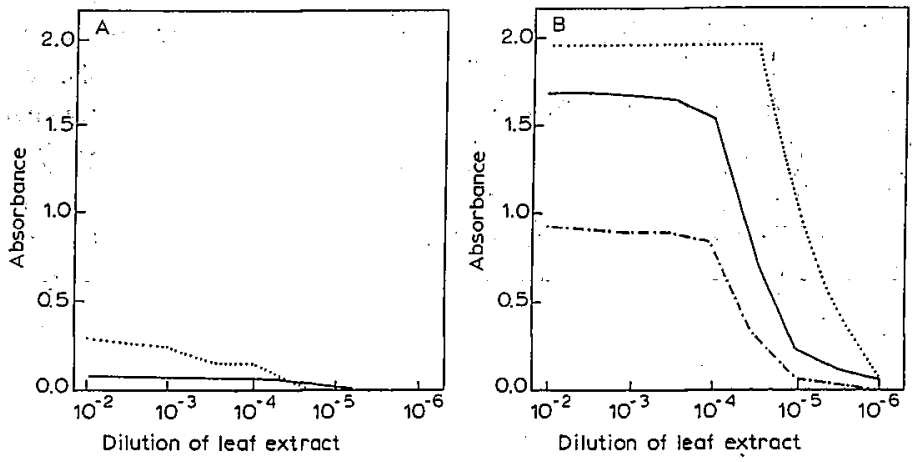

Fig. 2. Comparison of bromothymol blue (BTB) (-), starch-iodine complex (SIC) $(\cdots \cdots \cdot)$, and the mixed $\mathrm{pH}$ indicator of bromocresol purple and bromothymol blue (-......) for measurement of penicilloic acid in the penicillinase-based ELISA. Leaf extracts of healthy (A) and PMV-infected (B) peas were used in the DAC-ELISA with penicillinase-labeled rabbit Fc-specific antibodies at 1:5000 dilution. Sodium penicillin-G was used at $0.5 \mathrm{mg} / \mathrm{ml}$ in $\mathrm{BTB}$ or mixed $\mathrm{pH}$ indicator based substrate mixture and at $0.06 \mathrm{mg} / \mathrm{ml}$ in the SIC based substrate mixture. Absorbance values were measured at $620 \mathrm{~nm}$ for BTB and SIC, and for the mixed indicator at $450 \mathrm{~nm}$. Each point represents the mean of the absolute absorbance values of three replicate wells, obtained by deducting the mean absorbance values of three buffer controls from the absorbance of the test sample. 
After standardizing the substrate system, BTB, mixed $\mathrm{pH}$ indicator of $\mathrm{BCP}+\mathrm{BTB}$, and SIC were further tested for their suitability in PNC-based ELISA, using various dilutions of PMV-infected and healthy pea leaf extracts. Results presented in Fig. 2 indicate that the SIC detected PMV at a higher dilution $\left(10^{-5.0}\right)$ of plant extract than both $\mathrm{pH}$ indicators $\left(10^{-4.5}\right)$. Higher absorption values for extracts from healthy plants were obtained when SIC was used. Joshi et al. (1978) also observed non-specific reactions, which they attributed to the instability of the SIC. So in each test with SIC, healthy plant extracts should be used as negative controls. Absorption values with BTB and with mixed indicator of $\mathrm{BCP}+\mathrm{BTB}$ for intermediate dilutions of plant extract were linear, thus indicating the suitability of these indicator dyes in quantitative assays. In the case of SIC, there was a sharp decrease in the absorption value in the end point dilution. Also, the decrease in dark blue color in wells containing detectable amount of virus was not gradual, and thus the SIC system could only be recommended for qualitative assays.

\section{Stability of BTB-based substrate mixture}

ELISA plates coated with PMV and stored at $-20^{\circ} \mathrm{C}$ were used in each assay to evaluate substrate mixture stored for different lengths of time. Substrate mixture containing $\mathrm{BTB}$ and sodium penicillin-G was prepared and stored at $4^{\circ} \mathrm{C}$. Before use, the substrate mixture was brought to room temperature and the $\mathrm{pH}$ was adjusted to 7.2. The results showed that the substrate mixture can be stored for at

\section{TABLE 1}

Comparison of alkaline phosphatase (ALP), horseradish peroxidase (HRP), and penicillinase (PNC) as enzyme labels in ELISA for detecting tomato spotted wilt virus in peanut leaves ${ }^{\mathrm{a}}$

\begin{tabular}{|c|c|c|c|c|c|c|}
\hline \multirow{3}{*}{$\begin{array}{l}\text { Dilution of } \\
\text { leaf extract }\end{array}$} & \multicolumn{6}{|c|}{ Absorbance values ${ }^{c}$} \\
\hline & \multicolumn{2}{|l|}{ ALPd } & \multicolumn{2}{|l|}{ HRPe } & \multicolumn{2}{|l|}{$\mathrm{PNC}^{\mathrm{I}}$} \\
\hline & Healthy & Infected & Healthy & Infected & Healthy & Infected \\
\hline $10^{-2.5}$ & 0 & $0.75 \pm 0.022$ & $0.08 \pm 0.005$ & $1.54 \pm 0.034$ & $0.04 \pm 0.038$ & $0.94 \pm 0.030$ \\
\hline $10^{-3.0}$ & 0 & $0.69 \pm 0.020$ & $0.02 \pm 0.009$ & $1.26 \pm 0.028$ & $0.03 \pm 0.024$ & $0.88 \pm 0.047$ \\
\hline $10^{-3.5}$ & 0 & $0.26 \pm 0.001$ & $0.01 \pm 0.010$ & $0.43 \pm 0.012$ & $0.02 \pm 0.040$ & $0.36 \pm 0.021$ \\
\hline $10^{-4.0}$ & 0 & $0.03 \pm 0.006$ & $0.01 \pm 0.006$ & $0.11 \pm 0.006$ & $0.02 \pm 0.023$ & $0.09 \pm 0.009$ \\
\hline $10^{-4.5}$ & 0 & $0.01 \pm 0.006$ & $0.01 \pm 0.009$ & $0.04 \pm 0.01$ & $0.03 \pm 0.022$ & $0.04 \pm 0.038$ \\
\hline
\end{tabular}

"The DAC-ELISA system was used with enzyme-labelled rabbit FC-specific antibodies produced in goats. The ALP, HRP, and PNC conjugates were used at 1:1000, 1:1000 and 1:5000 dilutions, respectively. ${ }^{b}$ Based on the original weight of the tissue.

'Each value represents the mean of absolute absorbance values of three replicate wells, obtained after deducting the mean absorbance value of three buffer controis.

"Values were measured at $405 \mathrm{~nm}$.

'Values were measured at $450 \mathrm{~nm}$.

'Values were measured at $620 \mathrm{~nm}$. 
least 14 days without any detectable loss in sensitivity. However, the indicator solution without penicillin-G was stable for over 9 months at $4^{\circ} \mathrm{C}$.

Comparison of $A L P, H R P$, and PNC-based ELISAs for detecting $M M V, P M V$, and TSWV

The PNC-based ELISA, utilizing BTB indicator, was compared for detecting TSWV, PMV, and MMV. Results are presented in Table 1 and Fig. 3. Assays with the PNC-based ELISA were as sensitive as those of analogous assays performed with ALP and HRP. for the three plant viruses. Nevertheless, the PNC and HRP systems were more convenient for visual scoring of results than was the ALP system.

Although Sigma PNC was used in all the experiments, we also tried an enzyme preparation (ELISA grade) obtained as a free sample from Hindusthan Antibiotics Ltd. (HAL), Pimpri, Maharashtra, India. In order to achieve results similar to those obtained with the Sigma preparation it was necessary to use the IgG labeled with the HAL preparation, at a lower dilution (1/2000). However, the titres obtained in detecting PMV were the same with both the Sigma and the HAL preparations.

Our results show that the PNC-based ELISA is suitable for detection of plant viruses. The cost of substrate and enzyme component of ELISA while using PNC is less than a seventh of that using ALP. Additionally; when PNC was used with $\mathrm{pH}$ indicators, it was suitable for quantitative virus estimation. The PNC-substrate mixture, ready to use, could be stored for longer intervals than those of ALP and HRP. For scoring the ELISA results visually, the PNC-ELISA is comparable to
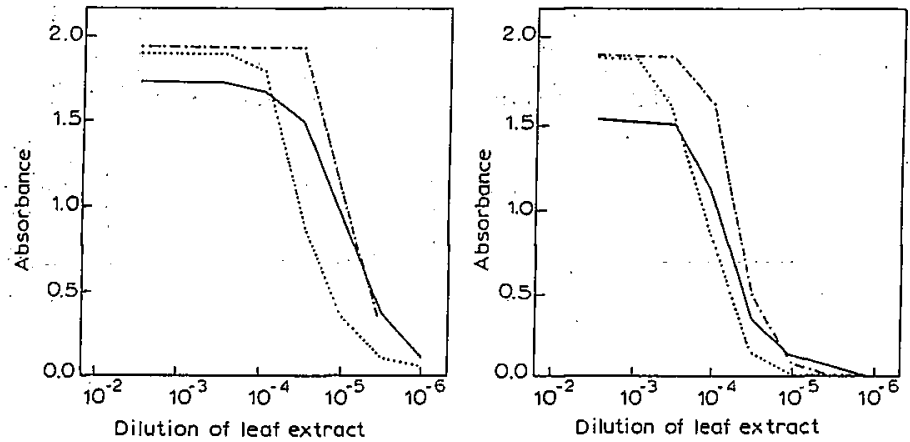

Fig. 3. Comparison of alkaline phosphatase (ALP) (…), horseradish peroxidase (HRP) ( - - - - ), and penicillinase (PNC) (- ), in detecting maize mosaic virus (MMV) in infected sorghum leaves (left panel) and peanut mottle virus (PMV) in infected peas (right panel). The DAC-ELISA system was used with rabbit Fc-specific antibodies labeled with ALP, HRP, and PNC at 1:1000, 1:1000, and 1:5000 dilutions, respectively. Absorbance values for substrates of ALP, HRP, and PNC were recorded at 405,450 and $620 \mathrm{~nm}$, respectively. Each point represents the mean of the absolute absorbance values of three replicate wells, obtained by deducting the mean absorbance values of three buffer controls from the absorbance of test sample. Values obtained using healthy plant extracts were close to that of buffer controls. 
the HRP system and superior to the ALP system. Although the stability of PNC conjugates prepared by the single step glutaraldehycle method was not critically examined in this investigation, we have been able to use a conjugate stored in a $1 \%$ BSA solution in PBS for more than 5 months at $4{ }^{\circ} \mathrm{C}$; without any detectable loss in the enzyme actiyity. However, the enzyme conjugate at working dilution (1:5000), stored at $4^{\circ} \mathrm{C}$, rapidly lost enzyme activity.

PNC has also been used for labeling biotin and used in conjunction with streptavidin for improving the sensitivity of the ELISA (Yolken et al., 1984). We are currently testing this procedure for PNC-based ELISA, particularly for the detection of viruses present at extremely low concentrations.

\section{Acknowledgements}

We are grateful to Dr. A.J. Gibbs, Research School for Biological Sciences, Australian National University, and Dr. D. McDonald, Legumes Pathology, International Crops Research Institute for the Semi-Arid Tropics (ICRISAT), for their helpful comments on the manuscript.

\section{References}

Barbara, D.J. and Clark, M.F. (1982) A simple indirect ELISA using $F\left(a b^{\prime}\right)_{2}$ fragments of immunoglobulins. J. Gen. Virol: 58, 315-322.

Clark, M.F. and Adams, S.N. (1977) Characteristics of the microplate method of enzyme-linked immunosorbent assay for the detection of plant viruses. J. Gen. Virol. 34, 475-483.

Clark, M.F. and Bar-Joseph, M. (1984) Enzyme immunosorbent assays in plant virology. In: K. Maramorosch and H. Koprowski (Eds), Methods in Virology, pp. 51-85. Academic Press, New York.

Houbs, H.A., Reddy, D.V.R., Rajeshwari, R. and Reddy, A.S. (1987) Use of direct antigen coating method and protein A coating ELISA procedures for detection of three peanut viruses. Plant Dis. 71, 747-749.

Joshi, U.M., Raghavan, V., Zemre, G., Sheth, A.R., Borkar, P.S. and Ramachandran, S. (1978) In: S.B. Pal (Ed.), Enzyme-labelled Immunoassay of Hormones and Drugs, pp. 233-245. Walter de Gruyter, Berlin.

Premier, R.R., Cox, J.C., Aitken, D.P. and Healey, K. (1985) An evaluation of the use of a pH indicator for the detection of $\beta$-lactamase in enzyme immunoassay. J. Inmmunol. Methods 83, 371-377.

Ross, W.G. and O'Callaghan, C.H. (1975) $\beta$-Lactamase assays. In: J.H. Hash (Ed.), Methods in Enzymology, pp. 69-85. Academic Press, New York.

Talwar, G.P., Gaur, A., Singh, A.K. and Gupta, S.K. (1983) Two simple and sensitive methods for detection of pregnancy and $h c G$ synthesizing tumours amenable to both qualitative and quantitative assays. Indian J. Med. Res. 77, 231-238.

Yolken, R.H., Wee, S.B. and van Regenmortel, M.Y. (1984) The use of beta-lactamase in enzyme immunoassays for detection of microbial antigens. J. Immunol. Methods 73, 109-123. 